\title{
Correlation Between Some Cognitive Processes and Reading Disability in Middle Childhood, Late Childhood and Early Adolescence
}

\author{
Fadia Elwan ${ }^{1}$, Shaaban Gaballah ${ }^{1}$ and Abdel Gawad Khalifa ${ }^{2 *}$ \\ ${ }^{1}$ Department of Psychology, Cairo University, Egypt \\ ${ }^{2}$ Institute of Psychiatry, Ain Shams University, Egypt
}

Submission: May 23, 2020; Published: July 27, 2020

*Corresponding author: Abdel Gawad Khalifa, Department of Psychiatry, Ain Shams University Hospitals, Cairo, Egypt

Abstract

Reading is vital for academic achievement, social participation and learning to read is one of the most important educational milestones in a child's development. A cognitive processing approach may provide greater sensitivity to the problems of children affected by Reading disability, the Planning, Attention, Simultaneous and Successive (PASS) theory as operationalized by the Cognitive Assessment System (CAS) seems to provide an attractive diagnostic tool for children affected by reading disability.

Aim: Present study aims to reveal the Correlation between Some Cognitive Processes and Reading Disability in children with reading disability and normal reader.

Patients and methods: Ninety dyslexic children were recruited from the Institute of Psychiatry; they fulfilled the Diagnostic and Statistical Manual of Mental Disorders, 5th ed. criteria for reading disability. We compared them with 90 normal controls for cognitive functions. We assessed them using the Cognitive Assessment System (CAS) and Battery of Reading Disability.

Results: The present study demonstrating that there is a significant correlation between planning and reading comprehension , also between successive processes and word reading for the sample of children with reading disability, while a significant correlation was found between planning and each of word recognition, word reading, sentence reading and reading comprehension.

Conclusion: The results of the study showed a significant correlation between some cognitive processes and reading difficulties. It also showed that cognitive processes that are correlated to reading difficulties are different among normal children than those with reading disabilities

Keywords: Reading disability; Cognitive processes; PASS theory; Cognitive assessment system (CAS)

\section{Introduction}

Developmental dyslexia are a specific neurodevelopmental learning disorder [1] estimated to affect $6-17 \%$ of the population [2]. They show unexpected difficulties in reading tasks if compared with their cognitive skills, age, intelligence, and level of education [3]. Dyslexia is characterized by word recognition and spelling deficits and recent research has also underscored that individuals with dyslexia, as opposed to control readers, exhibit difficulties in performing sequential procedural tasks and learning from feedback $[4,5]$. Over the years, evidence for difficulties among dyslexic readers in several systems relevant to reading has been accumulated. A wealth of studies suggests that the main source of their word decoding deficit lies in difficulties with the phonological system, which is responsible for the use of information of the sound structure of language for processing written and spoken language $[4,5]$. Much research on dyslexia demonstrated that it involves multiple cognitive-linguistic deficits; the majority of these studies focused on phonological processing, including phonological awareness, rapid automatized naming, and verbal short-term memory in most languages tested [6].

Neuroimaging research has revealed that reading is performed by a left-hemispheric network of frontal, temporoparietal and occipito-temporal cortical regions responsible for mapping visual (orthographic) information onto auditory (phonological) and conceptual (semantic) representations [7,8]. Intelligence, assessed with traditional IQ tests, has been heavily criticized as insufficient to account for individual differences in reading $[9,10]$. It has also been argued that when intelligence is operationalized in terms of cognitive processes it enhances our understanding of reading [11]. The purpose of this study was to examine the connection of 
cognitive processes, namely Planning, Attention, Simultaneous, and Successive with reading disability. The PASS theory is operationalized in the Cognitive Assessment System (CAS) which is a measure of cognitive ability designed as an alternative to traditional intelligence measures. The CAS measures intelligence redefined as essential cognitive processes called PASS [12]. These processes were derived from Luria's neuropsychological theory of brain functions. Luria postulated that there were three functional units of the brain. The first functional unit (i.e. brainstem and subcortical regions of the brain) was responsible for arousal and sustained attention. The second functional unit involved simultaneous and successive coding processes (i.e. central cortex region of the brain) and the third functional unit (i.e. frontal-lobe region of the brain) involved formulating, regulating, and verifying plans [13]. Based upon the work of Luria, Naglieri and Das defined intelligence using the PASS constructs and operationalized these processes in the CAS [14]. This theory takes the cognitive processing perspective of one's abilities, which assumes that PASS processes are the basic cognitive functions that allow students to perform a variety of academic tasks [15].

\section{Planning}

This process provides the means to solve problems of varying complexity and may involve attention, simultaneous, and successive processes as well as knowledge and skills. Planning is central to all activities for which the individual has to determine how to solve a problem, including self-monitoring and impulse control as well as plan generation. Success on CAS Planning tests requires the child to develop a plan of action, evaluate the value of the method, monitor its effectiveness, revise or reject a plan to meet the demands of the task, and control the impulse to act without careful consideration. All of the CAS Planning subtests require the use of strategies for efficient performance and the application of these strategies to novel tasks of relatively reduced complexity.

\section{Attention}

Attention is a mental process by which the individual selectively focuses on particular stimuli while inhibiting responses to competing stimuli presented over time. All CAS tests included on the Attention scale demand focused, selective, sustained, and effortful activity. Focused attention involves directed concentration toward a particular activity, and selective attention is important for the inhibition of responses to distracting stimuli. Sustained attention refers to the variation of performance over time, which can be influenced by the different amount of effort required to solve the test. All CAS Attention subtests present children with competing demands on their attention and require sustained focus [16].

\section{Simultaneous processing}

Simultaneous Processing. Simultaneous processing allows the person to integrate separate stimuli into a whole or see parts as an interrelated group. An essential dimension of simultaneous processing is that all of the separate elements are interrelated into a whole. For this reason, simultaneous processing tests have strong spatial and logical aspects. The spatial aspect of simultaneous processing includes perception of stimuli as a whole as in a recognizable geometric design. Simultaneous processing is similarly involved in grammatical statements that demand the integration of words into a whole idea. This integration involves comprehension of word relationships, prepositions, and inflections so the person can obtain meaning based on the whole idea. Simultaneous processing tests in the CAS require integration of parts into a single whole and understanding of logical and grammatical relationships. These processes are used in tests that involve nonverbal and verbal content, and recall of the stimuli, but the essential ingredient is simultaneous processing.

\section{Successive processing}

The essence of successive processing is the organization of stimuli into a specific serial order that forms a chain-like progression. Successive processing is required when a person must arrange things in a strictly defined order, where each element is only related to those that precede it and these stimuli are not interrelated. Successive processing involves both the perception of stimuli in sequence and the formation of sounds and movements in order. For this reason, successive processing has strong sequential components and is involved with the syntax of language, for example. All CAS Successive tests demand use, repetition, or comprehension based on order [17].

\section{Hypothesis}

There is a correlation between some cognitive processes and reading disability.

\section{Aim of the Study}

This study aimed to demonstrate a correlation between some cognitive processes and reading disability.

\section{Subjects and Methods}

\section{Participants}

The sample for the current study consisted of 180 male students, who were divided into two groups:

A: group of the participants with reading disabilities: This group is formed from 90 males, whose intelligence quotients ranged between 90 and 110 on the abbreviated version of Wechsler Intelligence Scale for Children. They were selected from the institute of Psychiatry - Ain Shams University. The participants were diagnosed with Reading disabilities by a psychiatrist according to the Diagnostic and Statistical Manual of Mental Disorders, 5th ed. (DSM-V) criteria for reading disability. The participants were not suffering from any other behavioral or emotional disorders. The participants' age ranged between 7 till 15-year-old, with mean age 10.33 and Standard deviation 0.54 . 
They were enrolled in primary 2, 3, 4, 5, 6 and first preparatory grade till the third preparatory grade.

B: group of the participants with normal reading: This group is formed from 90 males whose intelligence quotients ranged between 90 and 110 on the abbreviated version of Wechsler Intelligence Scale for Children. They were selected from schools which are equal to the schools of the participants with reading disability. The participants were not suffering from any behavioral or emotional disorders. The participants' age ranged between 7 till 15-year-old, with mean age 10.26 and Standard deviation 0.77 . They were enrolled in primary $2,3,4,5,6$ and first preparatory grade till the third preparatory grade (Table 1 ).

Table 1: The characteristics of the participants with reading disability and control.

\begin{tabular}{|c|c|c|c|c|}
\hline \multirow{2}{*}{} & \multicolumn{2}{|c|}{$\begin{array}{c}\text { Children with Reading Disability } \\
\text { N=90 }\end{array}$} & \multicolumn{2}{c|}{$\begin{array}{c}\text { Normal Children } \\
\text { N= 90 }\end{array}$} \\
\cline { 2 - 6 } & $\mathbf{M}$ & SD & M & SD \\
\hline Age & 10.33 & 0.54 & 10.26 & 0.77 \\
\hline IQ & 100.10 & 3.40 & 100.13 & 3.05 \\
\hline Socio-economic level & 24.20 & 3.48 & 23.86 & 4.25 \\
\hline
\end{tabular}

The following conditions were considered while selecting the entire participants:

i. Normal senses.

ii. The absence of any medical diseases.

iii. The equality of the socio-economic level between the two groups.

iv. The equality of the educational system between the two groups.

v. The equality of students' number in each educational grade between the two groups.

\section{Tools}

The sample studied was subjected to the following:

i. The abbreviated version of Wechsler Intelligence Scale for Children (WISC).

ii. Fahmy and El-Sherbini's Social Classification Scale: participants were classified into social class 1, 2, 3, and 4 according to an Egyptian classification developed by Fahmy and El-Sherbini [18]. The classification is based on the following parameters: education of the father, education and work of the mother, income, crowding index, and sanitation.

iii. Reading Disability Battery (designed by the researcher)

The battery consists of 5 subtests which are

a. Word Recognition Test: The test consists of 45 items; each item is formed of a picture and 4 words. The participants are asked to point to the correct word that describes the picture above. Each item is presented for 10 seconds. 1 mark is given for each correct answer while the wrong answer is scored with 0 . The height score that can be achieved is 45 .

b. Word Reading Test: The test consists of 45 words which are gradually presented according to their difficulty. Each word is written on a card and the participant is asked to read the words clearly and loudly with consideration to the linguistic and the grammatical rules. Noting that each card is presented for 5 seconds. The answers are rated from $0-2$ according to their accuracy. The height score that can be achieved is 90 .

c. Sentences Reading Test: The test consists of 36 sentences which are gradually presented according to their difficulty. Each sentence is written on a card and the participant is asked to read the sentences clearly and loudly with consideration to the linguistic and the grammatical rules. Noting that each card is presented for 10 seconds. The answers are rated from $0-2$ according to their accuracy. The height score that can be achieved is 72 .

d. Reading Comprehension Test: The test consists of 4 passages which are gradually presented according to their difficulty. The participants are asked to read the passages then to answer 4 multiple choices questions that follow each passage. 1 mark is given for each correct answer while the wrong answer is scored with 0 . The height score that can be achieved is 16

e. Reading Disability Rating Scale: The scale consists of 25 items that reflects different patterns of behaviors that Children with reading disabilities represent while reading. Parents are asked to read each item carefully and rate it according the severity of the reading disability. The Rating scale ranges from 1 to 5 .

\section{The psychometric characteristics of the Reading Disability Battery}

a. Validity: the validity sample consisted of 30 males with reading difficulties and 30 males with normal reading ability. The equality between the two groups in age, IQ and the socioeconomic level were considered:

The validity was calculated by two ways:

Concepts validity: it was measured by the correlation between the score of each subtest and the full score that is derived from the 


\section{Psychology and Behavioral Science International Journal}

calculation of the entire reading subtests. The validity ratios are presented in the following table

The criterion validity it was measured by the correlation between the score of each subtest and the Reading Disability Rating Scale by Fathy Al Zayat, the validity ratios are presented in the following table (Table 2):

Table 2: Validity coefficients of the Reading disability tests for participants with Reading disability and participants with normal reading ability

\begin{tabular}{|c|c|c|c|}
\hline \multirow{2}{*}{ Serial } & \multirow{2}{*}{ Test } & \multicolumn{2}{|c|}{ Validity Rations } \\
\cline { 3 - 4 } & & RD participants & Normal Participants \\
\hline 1 & Word Recognition & 0.91 & 0.85 \\
\hline 2 & Word Reading & 0.79 & 0.85 \\
\hline 3 & Sentences Reading & 0.67 & 0.69 \\
\hline 4 & Reading Comprehension & 0.78 & 0.85 \\
\hline
\end{tabular}

The validity Ratios that are derived from both groups are mostly similar and fall in the moderate and the high range.

b. Reliability: It was measured through test- retest by the retest ranged between $10-15$ days. The reliability ratios are linear Pearson correlation. The duration between the test and illustrated in the following table (Tables 3 \& 4).

Table 3: The correlation between the score of Reading subtest and the Reading Disability Rating Scale by Fathy Al Zayat.

\begin{tabular}{|c|c|c|c|}
\hline \multirow{2}{*}{ Serial } & \multirow{2}{*}{ Test } & \multicolumn{2}{|c|}{ Validity Rations } \\
\cline { 3 - 4 } & & RD participants & Normal Participants \\
\hline 1 & Word Recognition & $0.57^{* *}$ & $0.60^{* *}$ \\
\hline 2 & Word Reading & $0.52^{*}$ & $0.64^{* *}$ \\
\hline 3 & Sentences Reading & $0.69^{* *}$ & $0.71^{* *}$ \\
\hline 4 & Reading Comprehension & $0.75^{* *}$ & $0.79^{* *}$ \\
\hline
\end{tabular}

The table reveals that the entire tests are moderately and highly correlated. Additionally, the validity Ratios that are derived from both groups are mostly similar.

Table 4: Test -retest reliability coefficients of the Reading disability tests for participants with Reading disability and participants with normal reading ability.

\begin{tabular}{|c|c|c|c|}
\hline \multirow{2}{*}{ Serial } & \multirow{2}{*}{ Test } & \multicolumn{2}{|c|}{ Reliability Rations } \\
\cline { 3 - 4 } & & RD participants & Normal Participants \\
\hline 1 & Word Recognition & 0.97 & 0.86 \\
\hline 2 & Word Reading & 0.93 & 0.96 \\
\hline 3 & Sentences Reading & 0.82 & 0.92 \\
\hline 4 & Reading Comprehension & 0.91 & 0.95 \\
\hline
\end{tabular}

The table reveals that the entire tests are highly reliable. Additionally, the Reliability Ratios that are derived from both groups are mostly similar.

\section{Cognitive Assessment System (CAS)}

The CAS is an individually administered test for children aged 5-17 years designed to measure four basic psychological processes. The CAS is organized according to the PASS theory and comprised of four scales: Planning, Attention, Simultaneous, and Successive, each set at a mean of 100 and S.D. of 15. The eight-subtest Basic Battery was used in this study. The CAS was standardized on a sample of 2200 children aged 5-17 years who were selected to reflect the demographics of the United States. The average Basic Battery reliability coefficients are as follows: Full Scale (.87), Planning (.85), Attention (.84), Simultaneous (.90), and Successive (.90) [19].
The CAS measures individual differences in cognition by examining the four distinct but interrelated cognitive processes articulated in the PASS theory of intelligence: planning, attention, simultaneous processing, and successive processing [20]. Components of the CAS battery reflect the distinction between (a) higher-order control processes used in planning and monitoring task performance (i.e., planning and attention) and (b) information-processing components that involve the movement of information through working memory (i.e., simultaneous and successive processing). For the present investigation we used the Basic Battery, which consists of two subtests for each of the four PASS cognitive processes. Planning subtests require individuals to engage in multiple self-regulatory processes such as creating, 
applying, monitoring, and revising plans of action while solving novel tasks. The attention subtests require the detection of particular stimuli and the inhibition of responses to distracting stimuli. Simultaneous processing subtests require individuals to integrate separate stimuli into a conceptual group or whole. Successive processing subtests require individuals to comprehend meaning as it is derived from the order of information [21].

\section{Data processing and statistical analysis}

All data were recorded and entered into a statistical package on a compatible computer and varied. Analysis was carried out using an SPSS, version 21. The results were tabulated, grouped, and statistically analyzed using the following tests-Descriptive statistics (for quantitative data), as we used mean (X) and \pm SD, Chi - Square Tests for socio economic states, and person correlation.

\section{Results}

There was no statistically significant difference in the social class between the two groups, with the majority of the children in the Dyslexic group in the middle social class (53.3\%), and the majority of the participants in the control group also in the middle social class $(50.3 \%)$, Chi - Square $=12.854$ not significant.

\section{Correlation between cognitive processes and reading skills}

Pearson correlation coefficient was calculated between the four cognitive processes and reading skills to investigate the correlation of the four cognitive processes that are included in PASS theory and reading skills. The results reveal a significant correlation between planning and reading comprehension $\left(.224^{*}\right)$, and between successive process and word reading $\left(236^{*}\right)$, while there is no significant correlation between the other variables in the group of reading disability (Tables $5 \& 6$ ).

Table 5: Correlation coefficients between the cognitive processes and reading skills in the group of children with Reading disability.

\begin{tabular}{|c|c|c|c|c|}
\hline Cognitive Processes & Word Recognition & Word Reading & Sentences Reading & Reading Comprehension \\
\hline Planning & .104 & .183 & .145 & $.224^{*}$ \\
\hline Simultaneous & .015 & .105 & .092 & .015 \\
\hline Attention & .063 & .149 & .093 & .092 \\
\hline Successive & .100 & $.236^{*}$ & .185 & .090 \\
\hline
\end{tabular}

The table reveals a significant correlation between planning and reading comprehension, and between successive process and word reading, while there is no significant correlation between the other variables.

Table 6: Correlation coefficients between the cognitive processes and reading skills in the group of normal readers.

\begin{tabular}{|c|c|c|c|c|}
\hline Cognitive Processes & Word Recognition & Word Reading & Sentences Reading & Reading Comprehension \\
\hline Planning & $.293^{* *}$ & $.325^{* *}$ & $.216^{*}$ & $.317^{* *}$ \\
\hline Simultaneous & .057 & .100 & .031 & .052 \\
\hline Attention & $.276^{* *}$ & .167 & $.207^{*}$ & $.243^{*}$ \\
\hline Successive & .103 & .120 & .106 & .169 \\
\hline
\end{tabular}

The previous table reveals a significant correlation between planning, word recognition $\left(.293^{* *}\right)$, word reading $\left(.325^{* *}\right)$, sentences reading $\left(216^{*}\right)$ and reading comprehension $\left(224^{*}\right)$, in the group of normal readers. Additionally, it reveals significant correlation between attention, word recognition $\left(.276^{* *}\right)$, sentences reading $\left(.207^{*}\right)$ and reading comprehension $\left(.243^{*}\right)$.

\section{Discussion}

The current study aimed to investigate the correlation between some cognitive processes, which are planning, simultaneous, attention and successive processes and reading skills, which are word recognition, word reading, sentences reading and reading comprehension, of the children with reading disability and normal readers. The results confirmed the hypotheses in the group of children with reading disability; as it was revealed a significant correlation between planning and reading comprehension, in addition to significant correlation between successive processes and word reading, while the results did not reveal any significant correlation between the other variables. On the other side, the results revealed a significant correlation among planning, word recognition, word reading, sentences reading and reading comprehension in the group of normal readers. Additionally, the results revealed significant correlation among attention, word recognition, sentences reading and reading comprehension.

These results may reflect that children with reading disability and normal readers rely on different cognitive processes during reading as it was revealed a significant correlation between planning and entire reading skills at normal readers, while planning was significantly correlated with reading comprehension only at the children with reading difficulties. This may indicate that children with reading difficulties rely on planning in severely difficulty tasks such as comprehension, while they may rely on other strategies in word recognition and word reading such as guessing. As for the absence of significant correlation between simultaneous process and reading skills it may due to the fact that the simultaneous process requires perceiving parts into a holistic manner, while most of the teaching methods in The Egyptian 
Schools depend on restricted methods that only require on memorizing and rehearsal; which rely on the successive process. The second possible explanation for the absence of significant correlation between simultaneous process and reading skills may due to the fact that the simultaneous process is related with the performance intelligence scale in Wechsler scale for intelligence, while the successive process is related with the verbal intelligence in Wechsler scale for intelligence. Noting that the IQ variable was controlled by using Wechsler scale for intelligence, thus there were not significant correlations between the simultaneous and successive processes and reading skills in both groups.

The analysis of the simultaneous and the successive processes reveals that the successive processes -as it was assessed in the current study- rely on the auditory memory, while the simultaneous processes rely on the processing speed for visual information. On the contrary the researches indicate that the planning and attention are not included in traditional intelligence scales such as WISC, Thus it was found significant correlations between planning and all reading skills in the group of the normal readers, as well as the correlation between attention, word recognition, word reading, sentences reading, and reading comprehension, but there were no Arabic studies that can be followed in interpreting these results. Correlation between some cognitive processes, which are planning, simultaneous, attention and successive processes and reading disability, were supported by some findings from the literature.

Planning and attention have also been shown to correlate significantly with reading [24]. Planning has been related to reading decoding and reading comprehension in studies with elementary school-aged students and was reported to become more highly correlated with reading achievement as students matured $[25 ; 26]$. Ramey's study with high school students also supported the importance of planning with a variety of reading tasks.

\section{Conclusion}

The aim of the present study was to investigate the Correlation between some cognitive processes, which are planning, simultaneous, attention and successive processes and reading disability. A sample of 180 Egyptian boys' students from grade 2 to grade 9 participated in this study, including 90 students who have reading disability and 90 normal control, matched in age, socioeconomic states and IQ. They were administered with The Cognitive Assessment System (CAS), which was used to measure the planning-attention-simultaneous processingsuccessive processing (PASS). The results revealed a significant correlation between planning and reading comprehension, in addition to significant correlation between successive processes and word reading, while the results did not reveal any significant correlation between the other variables. On the other side; the results revealed a significant correlation among planning, word recognition, word reading, sentences reading and reading comprehension in the group of normal readers. Additionally, the results revealed significant correlation among attention, word recognition, sentences reading and reading comprehension.

\section{Strength and Limitations}

Although our study was one of only a few to compare cognitive functions in children with reading disability and normal controls, our study was limited by the sample size; thus, caution should be exercised in generalization of the results of this study and more research should be carried out on larger samples to replicate these results. Another limitation of our study was that it was crosssectional in nature and although it helped identify associations, it was difficult to infer causality in relationships. A longitudinal study would help answer many questions in this area. It must also be taken into consideration that the study was conducted on a sample of males only, so it is difficult to generalize their results to the general public population.

\section{Authors' Contributions}

FE and SG conceived and designed the study and analyzed the data. AK wrote the first draft of the manuscript, interpreted the data, and wrote the final manuscript. All authors agreed with the results and conclusions of this article. All authors read and approved the final manuscript.

\section{Availability of Data and Materials}

All data and materials are available.

\section{Ethics Approval and Consent to Participate}

The study was approved by the Ethics Committee of the Institute of Psychiatry, Ain Shams University. The child and the parent agreed to participate in the research, after receiving detailed information about the research. Written informed consent for participation in the study was obtained (participants are children under 16 years old).

\section{Consent for Publication}

All authors have approved the manuscript for publication.

\section{References}

1. Kuhl U, Neef NE, Kraft I, Schaadt G, D€orr L, et al. (2020) The emergence of dyslexia in the developing brain. NeuroImage 211: 116633.

2. Aboud K.S, Barquero, LA, Cutting LE (2018) Prefrontal mediation of the reading network predicts intervention response in dyslexia. Cortex 101: $96-106$.

3. Marcuzzia C, Romero Naranjo FJ (2017) BAPNE Method, Developmental Dyslexia and Inclusive Education: Cognitive, Socio Emotional and Psychomotor Stimulation in Secondary School. A Practical Resource for Education within a Cross Curriculum. Procedia - Social and Behavioral Sciences 237: 1291-1298.

4. Wenande B, Een E, Petok JR (2019) Dyslexia-related impairments in sequence learning predict linguistic abilities. Acta Psychologica 199: 102903. 
5. Paz-Alonsoa PM, Olivera M, Lerma Usabiagaa G, Caballero Gaudesa C, Quiñonesa L, et al. (2018) Neural correlates of phonological, orthographic, and semantic reading processing in dyslexia. Neuroimage: Clinical 20: 433-447.

6. Wang L, Liu D, Chung KK, Yang H (2017) Development of lexical tone awareness in Chinese children with and without dyslexia. Contemporary Educational Psychology 49: 203-214.

7. Naglieri JA, Das JP (1997) Cognitive Assessment System. Riverside Publishing Company, Itasca, Illinois, USA.

8. Luria AR (1973) The working brain: An introduction to neuropsychology. Basic Books, New York, USA.

9. Joseph LM, McCachran ME, Naglieri JA (2003) PASS cognitive processes, phonological processes, and basic reading performance for a sample of referred primary-grade children. Journal of Research in Reading 26(3): 304-314

10. Dan Cai D, Li QW, Deng CP (2013) Cognitive processing characteristics of 6th to 8th grade Chinese students with mathematics learning disability: Relationships among working memory, PASS processes, and processing speed. Learning and Individual Differences 27: 120-127.

11. Naglieri JA (2001) Using the cognitive assessment system (CAS) with learning - disabled children, in Kaufman, A.S. and Kaufman, N.L. (Eds) Specific learning disabilities and difficulties in children and adolescents - psychological assessment and evaluation. Cambridge University Press, United Kingdom, pp. 141-177.

12. Naglieri JA, Das JP (2002) Practical Implications of General Intelligence and PASS 55 Cognitive Processes. In: RJ Sternberg, EL Grigorenko (Eds.), the General Factor of Intelligence How General Is It? Lawrence Erlbaum Associates, Inc., Publishers, Mahwah, New Jersey, US State, pp. $55-84$
13. Fahmy S, El-Sherbini AF (1988) Determining simple parameters for social classification for health research. Bull High Inst Pub Health 13: 95-108.

14. Naglieria JA, Goldsteinb S, Delauder BY, Schwebach A (2005) Relationships between the WISC-III and the Cognitive Assessment System with Conners' rating scales and continuous performance tests. Archives of Clinical Neuropsychology 20: 385-401.

15. Naglieri JA (1999) Essentials of CAS assessment.: Wiley, 1 New York, USA.

16. Fein EC, Day EA (2004) The PASS theory of intelligence and the acquisition of a complex skill: a criterion-related validation study of Cognitive Assessment System scores. Personality and Individual Differences 37: 1123-1136.

17. Rasha Mohammed Abdullah (2002) The diagnostic value of the CAS model as shown in the relationship between the PASS model and the academic achievement, unpublished Master Thesis, Girls College, Ain Shams University, Egypt.

18. Ayman Al-Deeb (2002) Guide of CAS Scale for Intelligence, The Anglo Egyptian Library, Cairo, Egypt.

19. Parrila RK, Kendrick ME, Papadopoulos TC, Kirby JR (1999) Efficacy of cognitive reading remediation program for at-risk children in grade 1 . Developmental Disabilities Bulletin 27(2): 1-31.

20. Leong CK, Cheng SC, Das JP (1985) Simultaneous-successive syntheses and planning in Chinese readers. International Journal of Psychology 20: 19-31.

21. Naglieri JA, Das JP (1987) Construct and criterion-related validity of planning, simultaneous, and successive cognitive processing tasks. Journal of Psychoeducational Assessment 5: 353-363.

\section{Your next submission with Juniper Publishers will reach you the below assets}

- Quality Editorial service

- Swift Peer Review

- Reprints availability

- E-prints Service

- Manuscript Podcast for convenient understanding

- Global attainment for your research

- Manuscript accessibility in different formats

( Pdf, E-pub, Full Text, Audio)

- Unceasing customer service

Track the below URL for one-step submission https://juniperpublishers.com/online-submission.php 